\title{
Open government ideologies in post-soviet countries
}

\section{Karin Hansson*, Anton Talantsev and Jalal Nouri}

Department of Computer and Systems Sciences, DSV Stockholm University,

DSV, P.O. Box 7003,

SE-164 07 Kista, Sweden

Email: khansson@dsv.su.se

Email: antontal@dsv.su.se

Email: jalal@dsv.su.se

${ }^{*}$ Corresponding author

\section{Love Ekenberg}

Department of Computer and Systems Sciences,

Stockholm University,

DSV, P.O. Box 7003,

SE-164 07 Kista, Sweden

and

International Institute for Applied Systems Analysis (IIASA),

Schlossplatz 1 - A-2361 Laxenburg, Austria

Email: lovek@dsv.su.se

\section{Tony Lindgren}

Department of Computer and Systems Sciences,

Stockholm University,

DSV, P.O. Box 7003,

SE-164 07 Kista, Sweden

Email: tony@dsv.su.se

\begin{abstract}
Most research in research areas like e-government, e-participation and open government assumes a democratic norm. The open government (OG) concept is commonly based on a general liberal and deliberative ideology emphasising transparency, access, participation and collaboration, but were also innovation and accountability are promoted. In this paper, we outline a terminology and suggest a method for how to investigate the concept more systematically in different policy documents, with a special emphasis on post-soviet countries. The result shows that the main focus in this regions OG policy documents is on freedom of information and accountability, and to a lesser extent on collaboration, while other aspects, such as diversity and innovation, are more rarely mentioned, if at all.
\end{abstract}

Keywords: open government; e-government; e-participation; democracy; diversity; deliberation; freedom of information; accountability; interoperability. 
Reference to this paper should be made as follows: Hansson, K., Talantsev, A., Nouri, J., Ekenberg, L. and Lindgren, T. (2016) 'Open government ideologies in post-soviet countries', Int. J. Electronic Governance, Vol. 8, No. 3, pp.244-264.

Biographical notes: Karin Hansson is a Researcher at the Department of Computer and Systems Sciences at Stockholm University with participatory methodologies and participatory processes online as research focus. Her main interest is how the volunteer spheres use ICT to strengthen participatory practices and how participatory cultures translate to technical systems.

Anton Talantsev is a PhD student at the Department of Computer and Systems Sciences at Stockholm University. His research interests lie within the areas of international project development, risk, and decision and policy analysis.

Jalal Nouri's research belongs to the research field of Technology Enhanced Learning and in particular he is interested in the use of ICT in the context of mathematics and science education. He is a Researcher at the Department of Computer and Systems Sciences at Stockholm University.

Love Ekenberg is a Professor at the Department of Computer and Systems Sciences, Stockholm University and Senior Research Scholar at the International Institute of Applied Systems Analysis, IIASA in Austria. He has primarily been investigating risk and decision analysis; i.e., the development of processes, products and methodologies within these areas in various industrial and public sectors.

Tony Lindgren is a Researcher at the Department of Computer and Systems Sciences at Stockholm University. His research is in the areas of risk and decision analysis, and data and text mining.

\section{Introduction}

Needless to say, there have, over the years, been a variety of suggestions for making government more transparent and participatory (see e.g., Chapman and Hunt, 2011; Cross, 1953), but more recently the preconditions for information sharing has changed and the technical possibilities for a more collaborative information production and sharing culture have consistently improved. As the educational level and the technological development have changed, the citizens' expectations on their governments have transformed as well. In particular, citizens request to a larger extent access to more information, transparency and services. Among various initiatives connected to this, the concept of open government (OG) has been strongly encompassed and promoted by various authorities, such as the above-mentioned Obama Administration as presented in Open Government Progress Report to the American People (2009).

In very general terms, the proponents of open government claims that it induces a shift from a focus on services and efficiency to more interoperability, openness and participatory dimension that the technology might enhance, a fundamental change of how governments operate as well as a deliberative and innovative use of various new technologies (Hansson et al., 2015). In such a form, the OG concept is explicitly promoted by the US Government and organisations based in the USA (Mcnutt and Pal, 
2011), as well by the European Commission (2013), the Government of Canada (2014) and Australia (Australian Government Department of Finance, 2010). These countries are also participating in the open government partnership (OGP, 2014), which is an international platform sponsored by private investors and partner states, at present gathering 63 member states across the world, foremost in North and South America and Europe and is claimed to be committed in defining and implementing shared principles for transparency, access and participation.

Open government is also promoted in China, in particular to make local governments accountable for environmental issues (Horsley, 2010; Li, 2011) and in 2003, China's first legislation for access to government information at the municipal level, the Guangzhou Municipal Provisions on open government information, took effect. This formally established the principle that "virtually all government information should be disclosed and that non-disclosure would be the exception" (Horsley, 2008, p.5). In 2004, Shanghai, Beijing, Shenzhen, Hangzhou, Chongqing, Chengdu and Wuhan followed Guangzhou's lead and adopted policies for local open government information. Later, in 2008, China adopted the Regulations of the People's Republic of China on open government information.

Among the post-soviet countries, Armenia, Azerbadjan, Estonia, Georgia, Latvia, Lithuania, Moldova and Ukraine are part of the open government partnership (OGP, 2014), and have committed to implement a more open government. In Russia, the concept has been promoted by the administration of Prime Minister Medvedev, who launched an open government initiative 2012 (Konkov, 2013). Kazakhstan was the first government in central Asia with an open government program and recently they opened an open data portal (Kaulanova, 2014).

Kyrgystan has also been working towards a more open government, for example making the local budget processes more transparent (Kasymova, 2013).

This can be seen as a promising global development of democratic institutions expressed and performed in plans and regulations.

From a policy perspective, the development is then obviously substantial, and it is interesting to see how the research arena looks like. Researchers are generally pragmatic and publications regarding open government in the more established e-government journals has grown significantly since Obama launched the concept in 2009 (see Figure 1).

The research is also foremost focused on cases in the USA (Hansson et al., 2015). Less research is done on cases in post-soviet countries. A more general investigation of e-government readiness in commonwealth of independent states (CIS) countries points towards the institutional barriers that needs to be removed for efficient implementations of more participatory governments, such as lack of motivation and education among civil servants, lack of coherent standards and more supportive legislation (Bershadskaya et al., 2013). Moreover, the lack of an independent public sphere and free media in central Asia, is also a hinder for a transparent open government. There is still a pervasive censorship, self-censorship, harassment and intimidation of journalists in countries such as Kazakhstan, Kyrgyzstan, Tajikistan, Turkmenistan and Uzbekistan (Freedman, 2005). Furthermore, the digital divide and corruption in the region is significant (Warf, 2014). Corruption and structural biases in the legal system is for example imminent in Kazakhstan, Kyrgyzstan and Tajikistan (Welton, 2011). 
Figure 1 The number of journal papers with open government as a topic in blue and number of citations in green, in the web of knowledge database (see online version for colours)

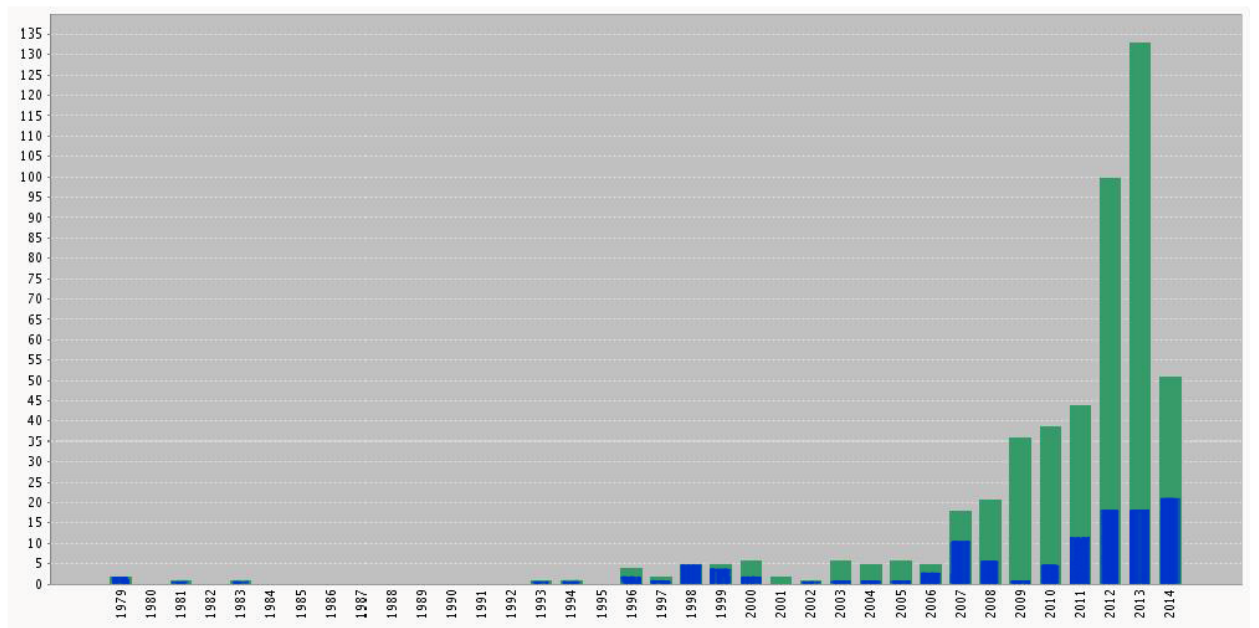

However, the institutional readiness for open government is larger in other parts of the region. Estonia is for instance often put forward as an example of successful e-government implementation (Dutta, 2006; Kalvet, 2012). Countries such as Moldova, Russia and Lithuania are also highly scored in the "Open Data Index scores of European countries" (Gomes and Soares, 2014).

These developments are obviously positive in many respects, and increased transparency and broad public participation are generally perceived as preconditions for some at least vague ideas of the concept of democracy, despite transparency is of course not equivalent to political freedom. As a trivial and pragmatic example (Relly and Sabharwal, 2009) note in their international cross-study on transparency that countries such as Singapore, Malaysia and Tunisia received high scores for transparency, while having low levels of democracy.

So, the situation is as usual more multifaceted and there are several problems connected with the concept of open government, including the risk that open data and crowd sourced information might be used for surveillance of the citizens as well as of the government. Secrecy might be needed in certain contexts and secrecy has also been a powerful strategy in relation to the state in different revolutionary movements (Birchall, 2012). The digital differentiation is another obvious problem regarding public participation in local decision processes. Decentralised decision making based on local participation in densely linked communities can also lead to conservatism (Cornford et al., 2013).

The OG concept is also perceived as an important part of the western liberal notion of democracy emphasising individual rights, such as privacy and freedom of speech. However, this definition of democracy is seldom explicitly expressed in field research in e-government or open government, which usually have a more bureaucratic focus, (cf., e.g., Hansson et al., 2015). 
Therefore, it is interesting to study how a concept of open government is interpreted, adopted and developed in the diverse institutional, cultural and social settings represented among post-soviet states. The various processes connected to these are complex and situated in, sometimes, very different contexts, and might not be suitable for comparisons. Nevertheless, the ideas about open government, expressed in public statues and plans, are possible to compare.

Independent of whether the ideologies in these plans bear any importance in the political and social setting of the countries in question, they are definitely part of a publicly expressed attempt to transform governments and have therefore a potential impact on the societies.

Therefore, to get a better grip of the ideologies expressed, we suggest in this paper an evaluation framework for open government ideologies, where we define methods and concepts and a chart where different notions of the concept can be aggregated and applied. Thereafter, we apply this framework on open governments' declarations and plans from post-soviet countries to see how different ideologies were emphasised in these documents.

\section{Data and method}

When constructing the framework for analysing the concept of open government, we started from the review in Hansson et al. (2015) of the literature on open government ranging over the last five years, positioning these in a critical context. This included 80 papers from over 40 different journals from the field of e-government, public administration and computer science, but also papers covering subjects like political science, law, medicine, education, environment, geography, infrastructure and philosophy.

We used the theory by Dahl (1989) to identify some core concepts and to analyse the material from a democracy perspective. Democracy, in Dahl's perspective, is an ongoing reflective process that is not only about collective decision making but also about who is a representative 'citizen' in the corresponding decision-making processes. Central to this process is understanding: the general aim that decision-making processes should be transparent for everyone and that everyone have the opportunities as well as the rights to express opinions. Thereafter, equal representation and the presence of a diversity of voices and sometimes conflicting perspectives is important on different levels; from the agenda setting to discussions and finally the voting. Thereafter follows basic democratic rights, such as to participate in the deliberative process of agenda-setting, discussions and voting.

By analysing these three aspects, transparency, diversity and deliberation, we can categorise the degree of democracy in a situation, but also which parts of the democracy concept under investigation that are emphasised.

Using a content analysis we have examined the way in which the three democratic notions of transparency, diversity and deliberation are addressed in this open government literature. We have also established a context of understanding by investigating how authors define open government, its benefits and its problems as well as which parts of the democratic process that have been emphasised and what types of solutions that are suggested to address these. During the process, the discourses were discussed and similar 
discourses were lumped together in different discourse types expressing similar ideologies. ${ }^{1}$ For example, the sentence "the public has the right to an easy access government data" is a discourse that can be seen as an expression of an ideology where greater transparency induces a stronger democracy.

To see how such different open government ideologies were expressed on an official level in post-soviet countries, we have collected publicly available open government plans and declarations. For countries that are part of the OGP, the partnership has been our main source of information. For countries outside the partnership we have used official government websites as our information source but also websites dedicated to open government where the government has been the sender of the information.

As these are the official declarations of OG, the documents' status is similar to statues or regulations, why there are one or, when adequate, two documents per country, reducing our study to a reasonably limited set of documents.

To ensure inter-rater reliability every document was independently analysed by two reviewers using the open government ideology evaluation framework described below. Thereafter, they were compared, analysed and discussed.

\section{The open government ideology evaluation framework}

When understanding how the open government concept is defined in the general research discourse, it is of course important to realise that the meaning and practices span from a way to make government more accountable and innovative to a way of generally improving democracy.

These meanings and practices, are summarised in the open government ideology evaluation framework (Table 1), which is grounded in the above-mentioned review of the democracy discourses in Hansson et al. (2015). As these research documents both describe different policy documents and real implemented cases, this gave us an overview not only over different ideologies but also how these were implemented in practice.

Table 1 OG ideology evaluation framework showing intersecting OG practices and ideologies expressed in different discourse types

\begin{tabular}{llll}
\hline & \multicolumn{3}{c}{ OG-Ideology } \\
\cline { 2 - 4 } OG-Practice & Democracy & Efficiency & Innovation \\
\hline Transparency & Freedom & Accountability & Interoperability \\
Participation & Diversity & Crowd sourcing & Crowd wisdom \\
Collaboration & Deliberation & Sharing culture & Problem solving \\
\hline
\end{tabular}

The framework describes the diversity of ideologies and discourses we found in the content analysis. We first examined how different aspects of democracy are addressed in the open government literature. To provoke and analyse our own pre-understanding of the concept, we also more closely studied papers differing from the mainstream open government discourse. This enabled a better understanding of alternative discourses and interpretation of the concept. 


\subsection{Facets of the open government concept}

We frame the various facets of the open government concept through two dimensions: OG-ideology and OG-Practice. The OG-ideology dimension is represented by three ideologies:

- democracy

- efficiency

- innovation

whereas the OG-practices are

- transparency

- participation

- collaboration

The intersections of the dimensions result in nine discourses representing different manifestations of the open government concept. Table 1 presents the nine discourses, constituting a framework for open government ideologies evaluation.

\subsection{Transparency, participation and collaboration}

The most cited document when defining open government in the last five years research is Open Government Progress Report to the American People (2009) from the Obama administration, defining open government as carrier of the three values transparency, participation and collaboration:

- Transparency. Government should provide citizens with information about what their government is doing so that government can be held accountable.

- Participation. Government should actively solicit expertise from outside Washington so that it makes policies with the benefit of the best information.

- Collaboration. Government officials should work together with one another and with citizens as part of doing their job of solving national problems ("Open Government Progress Report to the American People", 2009, p.5).

Other definitions of open government are similar, e.g., "participative, open, transparent, accountable, and collaborative" (Wimmer et al., 2012, p.1), or "the leveraging of information technologies to generate participatory, collaborative dialogue between policymakers and citizens" (Evans and Campos, 2013), Open Government Declaration (2011) defines open government as to "promote transparency, fight corruption, empower citizens, and harness the power of new technologies to make government more effective and accountable" (Open Government Declaration, 2011, p.1). Together these practices, can be contained within the more general definition transparency, participation and collaboration, why we will base our framework on these. We call them practices as they connote processes rather than a more goal-oriented discourse. 


\subsection{Democracy, efficiency and innovation}

In our framework ideology connotes the opinions or belief that justify the open government concept and explains its practices.

The OG concept is for example justified because it is supposed to promote democracy in one way or another. Such democracy ideology can, for example, imply that the practice of transparency is promoted through a freedom discourse that promotes the freedom of information as a precondition for democracy where all public information should be easy available. For example:

"This paper suggests how to achieve the primary goal of open government, which is to ensure that the American public has access to objective, relevant, and reliable information to help them arrive at informed judgements about issues and the government's role in tackling these problems." (Evans and Campos, 2013, p.2)

Such a discourse is often part of a democracy ideology where transparency is supposed to help citizens to consume government services by a better understanding of these services and how to access them.

Another discourse is that that the practice of broad public participation enables a diversity of voices and perspectives on different issues.

For example, in an paper about public participation in development of laws and regulations, a perspective is describes where the presumption is that people are different and therefore will look at the information differently as their certain life perspective form the way they define and handle a problem

\footnotetext{
"They [the participant] thus provide situated knowledge, by which we mean information about impacts, problems, enforceability, contributory causes, unintended consequences, etc. that are known by the commenter because of lived experience in the complex reality into which the proposed regulation would be introduced." (Farina et al., 2013, p.12)
}

The democracy ideology can also be expressed through a deliberation discourse where a more collaborative government ensures that decisions are grounded in a broad consensus developed in public dialogues. In this discourse, a broad participation in discursive practices online is an important democratic feature and the quality of this participation can be improved. It can for example be that moderators in an online forum can support a more deliberative discussion (Farina et al., 2013), or that some communities can create more informed and constructive discussions (Cornford et al., 2013). Furthermore, different democracy discourses can be expressed in the same statement, like in this paper about school choice and school performance in Moldova:

"This paper examines how it [OG] can advance the topic of freedom of educational choice, as it emphasises the importance of parents' involvement in the decision-making process at the school level.” (Paşcaneana, 2014, p.1)

Obviously, a discourse of freedom, is a precondition for a deliberation discourse, where, in particular, personal freedom is a precondition for a more collaborative practice, Efficiency is another ideology that often is expressed in the open government discourse. He practice transparency is for example seen as a way of making government more efficient by clarifying accountability and preventing corruption. 
Likewise, crowdsourcing, in the sense of a broad participation enabling a more distributed and efficient government, outsourcing simple tasks to citizens and private companies, is considered an expression for the efficiency ideology. For example, an online mapping portal as the Ordnance survey open data in Great Britain allows users to view, download or develop the data in a simple way, and thus contribute to an efficient development of data (Lilley, 2011). A third expression for the efficiency ideology is that collaboration creates a sharing culture between citizen and government and within governments, enabling a sharing of resources.

Another class of arguments for open Government concerns innovation. In the innovation ideology, transparency is of great importance and this discourse can be summarised as interoperability, meaning an easy and intentional sharing of information. This can for example be about making information available in a format that enables interoperability to enhance the development of new tools and services. Innovation is also expressed in the crowd wisdom discourse, meaning that broad participation enables more perspectives and possible solutions to problems. This discourse can be illustrated by the following quote about "Implementing open innovation in the public sector":

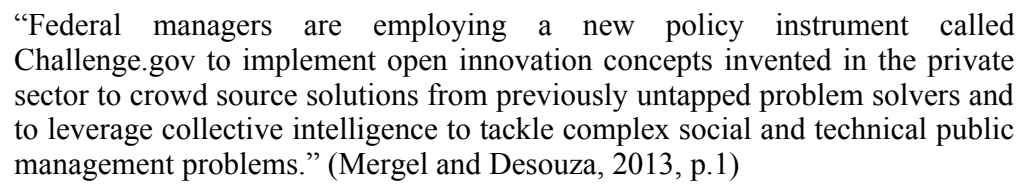

In the innovation ideology, collaboration means problem solving: A more collaborative government involves citizens and private companies in the problem solving process and thus is improving innovation.

In Table 1, we show how these ideologies (democracy, efficiency, innovation) can be described as intersecting with the practices (transparency, participation, collaboration) and be expressed in different discourses like greater information freedom, better accountability, interoperability, diversity of perspectives, crowd sourcing and crowd wisdom, public deliberation, sharing culture and collaborative problem solving.

Table 1 shows schematically various facets of the concept open government and its manifestations as well as how these can be understood in relation to each other. This provides us with a frame for analysing the various attempts to promote and implement the concept.

\section{Open government ideologies in the post-soviet region}

To further see how the open government ideology evaluation framework can be applied, we use it to identify different ideologies in official open government strategy documents from post-soviet countries. As the research on open government foremost is conducted in the USA usually expressing a more traditional liberal democratic ideology, it is interesting to investigate how the concept is developed when translated to former Soviet states. 


\subsection{Armenia}

The OGP's document “Action Plan by the Republic of Armenia" (2012) foremost describes different ambitions to make the government more efficient through greater transparency, but also more democratic and innovative in a general sense (Table 2).

Table 2 Open government discourses in the Open Government Partnership's "Action Plan by the Republic of Armenia" (2012). Words in bold are common discourses, black words are existing discourses and the grey/italics discourses does not exist

\begin{tabular}{llll}
\hline & \multicolumn{3}{c}{ Ideology } \\
\cline { 2 - 4 } Practice & Democracy & Efficiency & Innovation \\
\hline Transparency & Freedom & Accountability & Interoperability \\
Participation & Diversity & Crowd sourcing & Crowd wisdom \\
Collaboration & Deliberation & Sharing culture & Problem solving \\
\hline
\end{tabular}

Shared standards and simple rules are parts of this objective. The only time collaboration is mentioned it is when it comes to internal collaboration between different agencies. Open government is foremost described as a way to fight corruption. The plan lists different ways of ensure transparency and accountability and this quote summarise the document well:

"The main directions outlined in the policy include: increasing the effectiveness of state and local self-governance activities, anti-corruption and awareness raising campaigns, improving the public administration system, establishing a business friendly environment and a more effective governance system." (Action Plan by the Republic of Armenia, 2012, p.2)

However, the document also contains a deliberation discourse, where citizen collaboration is put forward as an explicit goal:

"Though the current legislation does not impede citizen participation in any way, the government is taking measures towards encouraging citizen participation and strengthening local and regional democracy. For this purpose, it is planned to make amendments in the acting law on local self-government, which will promote citizen participation, including participatory budgeting." (Action Plan by the Republic of Armenia, 2012, p.2)

Sharing information between agencies and with civil society is also put forward as a way of fighting corruption.

"A unit (Secretariat) will be established to assist the Council on the Fight against Corruption and its Monitoring Commission to perform efficiently their functions. It will also facilitate the establishment of cooperation between state bodies and civil society organizations." (Action Plan by the Republic of Armenia, 2012, p.11)

\subsection{Azerbaijan}

Just as in the Armenian document, the focus in Azerbaijan's "Open Government Initiative National Action Plan 2012-2015" is on democracy and efficiency through greater freedom of information and accountability through state transparency (Table 3 ). 
The innovative and problem solving aspect of OG through better interoperability is also emphasised.

Table 3 Open government discourses in Azerbaijan's “Open Government Initiative National Action Plan 2012-2015" (2012). Words in bold are common discourses, black words are existing discourses and the grey/italics discourses does not exist

\begin{tabular}{llll}
\hline & \multicolumn{3}{c}{ Ideology } \\
\cline { 2 - 4 } Practice & Democracy & Efficiency & Innovation \\
\hline Transparency & Freedom & Accountability & Interoperability \\
Participation & Diversity & Crowd sourcing & Crowd wisdom \\
Collaboration & Deliberation & Sharing culture & Problem solving \\
\hline
\end{tabular}

The document also state that the initiative is about participation with the help of new technologies:
"Enhancement of transparency in the state institutions of the Republic of Azerbaijan, provision of accountability, enlargement public participation and application of the new technologies are key principles of this initiative." ("Open Government Initiative National Action Plan 2012-2015 [Azerbaijan]", 2012, p.1)

However, participation is just briefly mentioned in the document, rather it is about developing information services and a culture of transparency. Focus is on a basic liberal notion of democracy; rights and information freedom. A larger involvement of companies and $\mathrm{NGO}$ is also mentioned:

\begin{abstract}
"Continuation of cooperation by the Government of the Republic of Azerbaijan with the local and foreign companies engaged in extractive industries, civil society institutions in order to ensure continuing implementation and development of the Extractive Industry Transparency Initiative in Azerbaijan." (I“Open Government Initiative National Action Plan 2012-2015 [Azerbaijan]”, 2012, p.5)
\end{abstract}

This document was the only that mentioned private entities as part of the transparency initiative, and not only the government. Thus open governance as a way to make private entities accountable to the people.

\title{
4.3 Estonia
}

The text in the "Estonia's Action Plan in Participating in the Open Government Partnership 2014-2016" (2014) is mainly about transparency and the arguments for this is democracy, efficiency and innovation (Table 4). There are no discussions about participation, but collaboration is suggested as a way to enhance democracy through deliberation and is also described as a way to make government more innovative.

This document consists in a pedagogic and explicit plan where the OG values as defined of the partnership are connected to clear goals, responsible actors and an evaluation plan. It starts with a simple definition of OG:

"Open Government means a fair and transparent execution of power in dialogue with citizens". ("Estonia's Action Plan in Participation in the Open Government Partnership", 2014, p.1) 
Table 4 Open government discourses in "Estonia's Action Plan in Participating in the Open Government Partnership 2014-2016" (2014). Words in bold are common discourses, black words are existing discourses and the grey/italics discourses does not exist

\begin{tabular}{llll}
\hline & \multicolumn{3}{c}{ Ideology } \\
\cline { 2 - 4 } Practice & Democracy & Efficiency & Innovation \\
\hline Transparency & Freedom & Accountability & Interoperability \\
Participation & Diversity & Crowd sourcing & Crowd wisdom \\
Collaboration & Deliberation & Sharing culture & Problem solving \\
\hline
\end{tabular}

Then the plan declares that participation is not such a big part of the partnerships OG declaration and that they want to make participation as their primary goal in this plan, since they already have created institutions supporting transparency and openness. Therefore, the focus is instead on better public engagement in public decision making. Secondly comes transparent budgeting and thirdly development of relevant services ("Estonia's Action Plan in Participation in the Open Government Partnership", 2014). An important part in including the public in decision processes is the availability of adequate and correct information. The aim here is for example:

"To improve the accessibility of information about Government plans, which would facilitate better participation, by linking e-channels to solve the according deficiencies which will be carefully assessed prior to action, and guided by the principle of user-friendliness.

People must be able to observe their opportunities for participation in various proceedings and thus to participate in more stages of proceedings". ("Estonia's Action Plan in Participation in the Open Government Partnership", 2014, p.11)

\subsection{Georgia}

The focus of Georgia's action plan is foremost to implement general e-government services and to prevent corruption, which is clearly an ambition, but about the emphasis is on e-services and on the provision of the technical tools needed to get access to internet. Freedom of information and accountability are explicit objectives and also a more collaborative and deliberative political process is emphasised (Table 5).

Table 5 Open government discourses in the Open Government Partnership's "Georgia action plan 2012-2013" (2012). Words in bold are common discourses, black words are existing discourses and the grey/italics discourses does not exist

\begin{tabular}{llll}
\hline & \multicolumn{3}{c}{ Ideology } \\
\cline { 2 - 4 } Practice & Democracy & Efficiency & Innovation \\
\hline Transparency & Freedom & Accountability & Interoperability \\
Participation & Diversity & Crowd sourcing & Crowd wisdom \\
Collaboration & Deliberation & Sharing culture & Problem solving \\
\hline
\end{tabular}

There is clearly a democracy ideology, but foremost concerning efficiency, emphasising the citizen as a consumer: 
"Georgian Government believes that - as a matter of principle - public service should not be different from the private service and should equally focus on the easiness, speed and quality.” (“Georgia Action Plan 2012-2013”, 2012, p.6)

However, the Georgian government do plan a platform where citizens will be able to express their opinions and submit e-petitions. But also here the focus is on transparency and efficiency.

\subsection{Kazakhstan}

Despite relatively matured e-government services, there is no official document specifically defined for the open government. The OG-related initiatives are mentioned in the context of informatisation and e-government. Therefore, we analysed the state program 'Information Kazakhstan - 2020' (The Ministry of Transport and Communications of Kazakhstan, 2013), which contains a section on 'Openness of state bodies'. In this text the discourses are about accountability and crowdsourcing, and interoperability is also mentioned (Table 6).

Table 6 Open government discourses in the 'Openness of state bodies' section in the "Information Kazakhstan - 2020" program (The Ministry of Transport and

Communications of Kazakhstan, 2013) and on the official open government webpage Open Government (n.d.)

\begin{tabular}{llll}
\hline & \multicolumn{3}{c}{ Ideology } \\
\cline { 2 - 4 } Practice & Democracy & Efficiency & Innovation \\
\hline Transparency & Freedom & Accountability & Interoperability \\
Participation & Diversity & Crowd sourcing & Crowd wisdom \\
Collaboration & Deliberation & Sharing culture & Problem solving \\
\hline
\end{tabular}

The objective statement for the section almost entirely focuses on accountability through e-government systems:
“Задача: повышение прозрачности и подотчетности деятельности государственных органов для удовлетворения прав и законных интересов граждан, бизнеса и общества в информации"
[Objective: To increase transparency and accountability of public authorities to meet the legitimate rights and interests in information for citizens, business and society] (The Ministry of Transport and Communications of Kazakhstan, p.15)

There is also mentioning of social web-platforms as a mechanism of citizens' participation in reforming and improving the state (see p.15).

Additionally, we analysed a page at the governmental website dedicated to the OG concept Open Government (n.d.). Along with accountability, the page emphasises transparency, especially free access to information, as well as, interoperability. It also mentions participation as a means for efficient decision and policy making.

\subsection{Lithuanian}

The core focus in "Action Plan for Lithuanian Participation in the International Initiative 'Open government Partnership"” is on transparency, especially freedom and deliberation, 
why the democracy ideology seems to be strong (Table 7). Participation and collaboration is also looked upon as a general democratic value, not only as a way of improving the government.

Table 7 Open government discourses in the Open Government Partnership's “Action Plan for Lithuanian Participation in the International Initiative 'Open Government Partnership"' (2012). Words in bold are common discourses, black words are existing discourses and the grey/italics discourses does not exist

\begin{tabular}{llll}
\hline & \multicolumn{3}{c}{ Ideology } \\
\cline { 2 - 4 } Practice & Democracy & Efficiency & Innovation \\
\hline Transparency & Freedom & Accountability & Interoperability \\
Participation & Diversity & Crowd sourcing & Crowd wisdom \\
Collaboration & Deliberation & Sharing culture & Problem solving \\
\hline
\end{tabular}

The document is a rather concrete plan stating in details how the goals will be achieved and by whom:
"We believe that an Open Government must put every effort to open up the information it holds to the public and to make it easily accessible and comprehensible. An Open Government should enable active public participation in the decision-making on the issues important for the Government and society and ensure a service quality satisfying the public needs as well as efficient and transparent use of public resources". ("Action Plan for Lithuanian Participation in the International Initiative 'Open Government Partnership'”, 2012, p.2)

\subsection{Republic of Moldova}

The open government discourses in the document "Open government partnership: Open government action plan 2012-2013 for the Republic of Moldova" are freedom of information, accountability, interoperability and deliberation (Table 8). Thus, transparency is the main goal but also collaboration to strengthen a more deliberative democracy.

Table 8 Open government discourses in "Open Government Partnership: Open Government Action Plan 2012-2013 for the Republic of Moldova" (2013). Words in bold are common discourses, black words are existing discourses and the grey/italics discourses does not exist

\begin{tabular}{llll}
\hline & \multicolumn{3}{c}{ Ideology } \\
\cline { 2 - 4 } Practice & Democracy & Efficiency & Innovation \\
\hline Transparency & Freedom & Accountability & Interoperability \\
Participation & Diversity & Crowd sourcing & Crowd wisdom \\
Collaboration & Deliberation & Sharing culture & Problem solving \\
\hline
\end{tabular}

This is an ambitious plan where different actions are described in details. It is also one of few plans more clearly describing various national open data projects. It also emphasises the importance of discussing and developing the regulations, and to include citizens in this process: 
"Ensuring a participatory decision making. Central public administration authorities will regularly publish and update relevant information about decision making process in the 'Transparency decision' section of their webpage. The online platform www.particip.gov.md will stimulate and streamline an effective public consultations process, by compelling central public administration authorities to post policy documents, draft legislation, information about time and format of public consultations and public officers responsible for consultations, etc." ("Open Government Partnership Open Government Action Plan 2012-2013 for the Republic of Moldova”, 2013, p.4)

\subsection{Russia}

The strongest expressed ideology in the Russian Federation policy document "Concept for Openness of Federal Authorities" (2014) of Russian Federation and the "Methodology for Monitoring and Evaluation of Openness of Federal Authorities" (2013), is efficiency, especially focusing on accountability but also suggesting ways to include the public in the data collecting and to create a more sharing culture (Table 9). Collaborative practices are also mentioned to support a more deliberative democratic process and to create a more innovative government.

Table 9 Open government discourses in the Russian Federation policy document "Concept for Openness of Federal Authorities" (2014) of Russian Federation, and in "Methodology for Monitoring and Evaluation of Openness of Federal Authorities" (2013)

\begin{tabular}{llll}
\hline & \multicolumn{3}{c}{ Ideology } \\
\cline { 2 - 4 } Practice & Democracy & Efficiency & Innovation \\
\hline Transparency & Freedom & Accountability & Interoperability \\
Participation & Diversity & Crowd sourcing & Crowd wisdom \\
Collaboration & Deliberation & Sharing culture & Problem solving \\
\hline
\end{tabular}

"The Concept for Openness of Federal Authorities" (2014) is a policy, which targets federal authorities. It defines key principles and strategic directions for OG in Russia, as well as, means for their implementation. Furthermore, the concept has a follow-up policy, namely "Methodology for Monitoring and Evaluation of Openness of Federal Authorities" (2013).

The methodology defines an integrated and structured assessment approach for the level of open government 'maturity' of the federal authorities. In essence, the approach evaluates the degree of fulfilment of the OG principles through the specified mechanisms and tools, which are defined in the Concept document. The evaluation approach is of particular interest, as this allows us to derive what is deemed to be higher level of OG achievement along with associated criteria.

Along with dominant focus on accountability, the "Concept for Openness of Federal Authorities" (2014) also strongly emphases participation and collaboration, such as direct involvement of diverse actors into the public policy formulation:

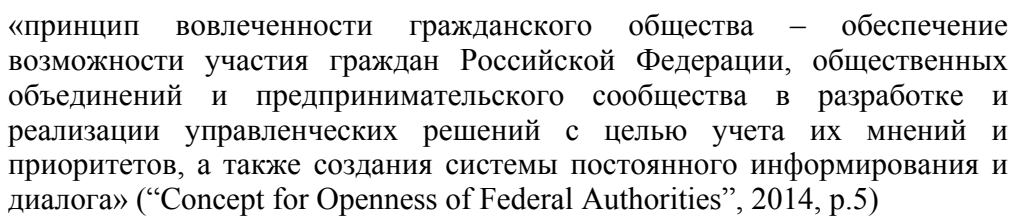


[The principle of involvement of civil society - providing opportunities for participation of citizens of the Russian Federation, NGOs and the business community in developing and implementing managerial decisions, in order to take into account their views and priorities, as well as establishing a system of continuous informing and dialogue.]

The methodology document further supports the 'deliberation' and 'problem solving' aspects. "Methodology for Monitoring and Evaluation of Openness of Federal Authorities" (2013) defines four maturity levels for the 'openness' of federal authorities. Along with other criteria each maturity level is evaluated through the collaboration and participation dimensions. As instance, the (first) "Preparatory level of openness" is characterised by
«низкий уровень общественного участия, который обычно состоит из одностороннего предоставления информации со стороны федерального органа исполнительной власти и при котором не требуется или не ожидается взаимодействия или вовлеченности институтов гражданского общества в процесс разработки и принятия решений»
[low level of public participation, which usually consists of a one-sided provision of information on the part of the federal authority, and the collaboration or involvement of civil society in decision-making is not required or expected] (p.9)

Whereas, the highest (fourth) 'Advanced level of openness' implies a broad deliberative process where the public is involved in the whole democratic process from identifying the problem, to discussion, decision making and implementation:

\begin{abstract}
«общественное участие строится на основе партнерства и подразумевает взаимную ответственность на каждом этапе процесса принятия совместных решений: разработки проекта, подготовки, принятия и реализации решений»

[The public participation is based on partnership and implies mutual responsibility at every stage of joint decision-making: drafting, preparation, adoption and implementation of decisions] (p.11)
\end{abstract}

\title{
4.9 Ukraine
}

The document "Action plan of Ukraine for implementation in Ukraine of the Open government partnership initiative" (2012) suggests a greater transparency to promote democracy and efficiency (Table 10). Practices such as transparency, participation and collaboration are also suggested as a way to create a more innovative state, and a stronger democracy is also put forward as an important goal.

Table 10 Open government discourses in the "Action Plan of Ukraine for Implementation in Ukraine of The Open Government Partnership Initiative"

\begin{tabular}{llll}
\hline & \multicolumn{3}{c}{ Ideology } \\
\cline { 2 - 4 } Practice & Democracy & Efficiency & Innovation \\
\hline Transparency & Freedom & Accountability & Interoperability \\
Participation & Diversity & Crowd sourcing & Crowd wisdom \\
Collaboration & Deliberation & Sharing culture & Problem solving \\
\hline
\end{tabular}


The document defines open government as the promotion of free exchange of public information, deliberation, problem solving and accountability:
"Ukraine fully shares the principles of the Open Government Declaration with regard to promotion of openness and transparency of state policies, engagement of civil society bodies into policy-making, introduction of high standards of professional integrity throughout the state administration." ("Action Plan of Ukraine for Implementation in Ukraine of The Open Government Partnership Initiative", 2012, p.1)

This document also places collaboration as a means for the reforms:

\begin{abstract}
In close partnership between the Government and with civic society bodies, it is planned to accomplish priority tasks aimed at increasing cooperation between government institutions and the public in making and implementing government decisions, providing access to public information, using effective instruments against corruption, improving government efficiency, including through extensive use of electronic technology." ("Action Plan of Ukraine for Implementation in Ukraine of The Open Government Partnership Initiative", 2012, p.1)
\end{abstract}

\title{
4.10 Overall summary
}

The overall summary of these documents shown in Table 11 is that the main ideologies expressed are democracy and efficiency. These objectives are foremost achieved through a greater transparency, for example by making data available online and changing the legislation as well as that the government's working processes so that they become more open for inspections. A more collaborative government, where participants and NGOs are included in the decision process and when different interests are collectively taken into account, is also often mentioned in the documents. Diversity as a democratic quality or a more sharing culture for higher efficiency is rarely mentioned and is not particularly taken into account, even less the promotion of effective policies for implementing schemes for inclusion of various groups and good practices for managing this nationally, regionally or locally. Participation for innovation is not mentioned at all, except for information provision, possible facilitating problem understanding, and to some extent consulting, in the sense of obtaining public feedback, but without particular empowerment mechanisms mentioned.

Table 11 Summary of open government discourses in Tables 2-10

\begin{tabular}{llll}
\hline & \multicolumn{3}{c}{ Ideology } \\
\cline { 2 - 4 } Practice & Democracy & Efficiency & Innovation \\
\hline Transparency & Freedom & Accountability & Interoperability \\
Participation & Diversity & Crowd sourcing & Crowd wisdom \\
Collaboration & Deliberation & Sharing culture & Problem solving \\
\hline
\end{tabular}

\section{Concluding remarks}

In this paper, we have introduces a framework for investigating democracy ideologies connected to a set of open government plans. By analysing current research trends in 
open government, we have developed a framework providing us with a structure of the promoted practices and ideologies contained in the concept of open government. This evaluation framework has then been used as a coding scheme to highlight prominent discourses in official documents about open government, primarily from post-soviet countries.

The framework is constructed from the different practices: transparency is the first practice. Thereafter comes participation, where governments should learn from broad and representative groups of NGOs, local communities, experts, relevant citizens and stakeholder organisations at large. The third practice is collaboration, i.e., a political framework where the participants actively collaborate to attain agendas, possibly using various enabling technologies facilitating citizen participation at large as well as between government agencies. These practices can be interpreted differently, for example transparency can be seen as a democratic value promoting the free access to governmental and other information generally. The freedom (of information) discourse is the most common discourse in the analysed documents. All countries documents, with the exception of Russia, contained frequent mentioning of derivatives of this discourse.

A democracy ideology can also mean that a participation of citizens and stakeholder organisations enable a diversity of perspectives and representation regarding various issues and that people has different abilities and experiences, which must be addressed, also in the sense of promoting support for empowering, e.g., marginalised groups. Despite the large digital divide in the region the diversity discourse is lacking in these documents. Instead it is a liberal ideology that dominates, where the potential problems with, e.g., the digital divide is either not mentioned or described as something that is possible to overcome. Here primarily the documents from Russia, but also from Azerbaijan, stands out as they emphasise a broad participation and methods to address a diversity of stakeholders.

These documents also had many instances of a deliberation discourse, indicating ambitions of an ideology promoting a collaborative government, where decisions are taken after long and careful consideration and public discussion.

The Azerbdjan document also mention private entities as part of the transparency initiative, which is interesting since there is a paradox in the open government concept where on one hand transparency is emphasised and on the other, a lot of services that have been governments responsibility is 'decentralised' to NGOs and private actors implying that previous public services become private and potentially less transparent. However, the oil industry is obviously an important actor to make accountable to the citizens.

Another ideology that that was common in the documents was efficiency, in the sense that governments can be more efficient, in particular through a higher transparency and by clarifying the accountability. However, efficiency through collaboration and participation, such as crowd sourcing, inclusion and a more sharing culture, was not common in the documents.

Another argument for open government (especially present in a North American context) is its capacity for innovation. This ideology is usually expressed in terms of interoperability, crowd wisdom and participatory problem solving. Interoperability was most common in the documents, in the sense of making adequate and relevant information available in a format enabling interoperability while enhancing development of new tools and services. Some documents also expressed a problem solving discourses, 
promoting more collaboration for improving innovation. This discourse was present in the documents from Ukraine, Russia and Estonia.

That the main focus in the majority of these open government plans is on transparency and accountability is maybe not very surprising. There is also in some cases an obvious interest in more collaborative governments, where participants and NGOs are included in the decision processes. As earlier research shows, the institutional barriers for e-government such as work culture, lack of coherent standards and supportive legislation are large in CIS countries (Bershadskaya et al., 2013). There is furthermore a lack of a free public sphere and civil rights in many parts of the region (Freedman, 2005), a significant corruption (Welton, 2011), and a substantial digital divide (Warf, 2014). The parts of the region where the institutional readiness for open government is larger, e.g., in Estonia, Moldova, Russia and Lithuania, participation had a more prominent role in the plans.

In conclusion, in this paper, using documents from post-soviet countries as data, we have outlined an open government terminology and showed how this can be utilised in a method for investigating this concept in policy documents. The result shows that the main focus of the open government policy documents in this region is on liberal rights, such as freedom of information and accountability, and to a lesser extent on forms for strengthen collaboration and deliberation, while other aspects, such as diversity or innovation, are rarely mentioned.

To further investigate how the open government concept is interpreted, adopted and developed, we need longitudinal case studies to situate this more theoretical contribution in the actual political and social reality of these societies. We hope this overview of open government ideologies can contribute to a reflexion on the underlying norms and values embedded in socio-technical practices, especially when translated into policies.

\section{References}

Action Plan by the Republic of Armenia (2012) Open Government Partnership. Retrieved 22 April, 2015, from http://www.opengovpartnership.org/file/983/download

Action Plan for Lithuanian Participation in the International Initiative 'Open Government Partnership' (2012) Open Government Partnership, Retrieved 9 April, 2015, from http://www.opengovpartnership.org/country/lithuania

Action Plan of Ukraine for Implementation in Ukraine of The Open Government Partnership Initiative (2012) http://www.opengovpartnership.org/sites/default/files/legacy_files/country_ action_plans/actionplanukraine.pdf (Retrieved 9 April, 2015).

Australian Government Department of Finance (2010) Declaration of Open Government, Retrieved 28 April, 2014, from http://www.finance.gov.au/blog/2010/07/16/declaration-opengovernment

Bershadskaya, L., Chugunov, A. and Dzhusupova, Z. (2013) 'Understanding E-government development barriers in cis countries and exploring mechanisms for regional cooperation', Lecture Notes in Computer Science (Including Subseries Lecture Notes in Artificial Intelligence and Lecture Notes in Bioinformatics), Vol. 8061 LNCS, pp.87-101.

Birchall, C. (2012) 'Transparency, interrupted: secrets of the left', Theory, Culture \& Society, Vol. 28, pp.60-84.

Chapman, R.A. and Hunt, M. (Eds.) (2011) Open Government: A Study of the Prospects of Open Government Within the Limitations of the British Political System, Routledge, Abingdon. 
Cornford, J., Wilson, R., Baines, S. and Richardson, R. (2013) 'Local governance in the new information ecology: the challenge of building interpretative communities', Public Money and Management, Vol. 33, No. 3, pp.201-208.

Cross, H.L. (1953) The People's Right to Know: Legal Access to Public Records and Proceedings, Columbia, U.P., Oxford, U.P.

Dahl, R.A. (1989) Democracy and Its Critics, Yale Univ. Press, New Haven, Retrieved from http://libris.kb.se/bib/8281677

Dutta, S. (2006) Estonia: A Sustainable Success in Networked Readiness?, The Global Information Technology Report 2006-2007, Palgrave Macmillan, Hampshire, UK, pp.81-90.

Estonia's Action Plan in Participation in the Open Government Partnership (2014) Open Government Partnership, Retrieved 8 April, 2015, from http://www.opengovpartnership.org/ country/estonia

European Commission (2013) A Vision for Public Services, Brussel, Retrieved 5 March, 2015, from http://ec.europa.eu/information_society/newsroom/cf/dae/document.cfm?doc_id $=3179$

Evans, A.M. and Campos, A. (2013) 'Open government initiatives: challenges of citizen participation', Professional Practice, Vol. 32, No. 1, doi: 10.1002/pam.

Farina, C.R., Epstein, D., Heidt, J.B. and Newhart, M.J. (2013) 'Regulation room: getting 'more, better' civic participation in complex government policymaking', Transforming Government: People, Process and Policy, Vol. 7, No. 4, pp.501-516.

Freedman, E. (2005) 'Coverage of central Asian political, press and speech rights issues by independent news websites', Asia Pacific Media Educator, Vol. 1, No. 16, pp.71-88, Retrieved from http://ro.uow.edu.au/cgi/viewcontent.cgi?article $=1034 \&$ context $=$ apme

Georgia Action Plan 2012-2013 (2012) Open Government Partnership, Retrieved 9 April, 2015, from http://www.opengovpartnership.org/country/georgia

Gomes, Á. and Soares, D. (2014) 'Open government data initiatives in Europe: northern versus southern countries analysis', ICEGOV '14 Proceedings of the 8th International Conference on Theory and Practice of Electronic Governance, ACM New York, New York, pp.342-350.

Government of Canada (2014) Canada's Action Plan on Open Government, Retrieved 28 April, 2014, from http://data.gc.ca/eng/canadas-action-plan-open-government

Hansson, K., Belkacem, K. and Ekenberg, L. (2015) 'Open government and democracy', Social Science Computer Review, Vol. 33, No. 5, pp.540-555, doi:10.1177/0894439314560847.

Horsley, B.J.P. (2008) China Adopts First Nationwide Open Government Information Regulations, pp.1-13.

Horsley, J.P. (2010) Update on China's Open Government Information Regulations: Surprising Public Demand Yielding Some Positive Results, FreedomInfo.Org, Retrieved 28 April, 2014, from http://www.freedominfo.org

Kalvet, T. (2012) 'Innovation: a factor explaining e-government success in estonia', Electronic Government, An International Journal, Vol. 9, No. 2, p.142.

Kasymova, J.T. (2013) Reforming Local Government in Developing Countries: Implementation of a Participatory Budgeting Process in Kyrgyzstan, The State University of New Jersey.

Kaulanova, A. (2014) The Rise of Open Data in Kazakhstan, The World Bank, Retrieved 7 May, 2015, from http://blogs.worldbank.org/ic4d/rise-open-data-kazakhstan

Konkov, A. (2013) Open Government Partnership: Go Russia?, Retrieved 2 May, 2015, from http://valdaiclub.com/politics/56561.html

Li, W. (2011) 'Self-motivated versus forced disclosure of environmental information in china: a comparative case study of the pilot disclosure programmes', The China Quarterly, Vol. 206, pp.331-351.

Lilley, B. (2011) 'The ordnance survey openData initiative', The Cartographic Journal, Vol. 48, No. 3, pp.179-182.

Mcnutt, K. and Pal, L.a. (2011) 'Modernizing government': mapping global public policy networks', Governance, Vol. 24, No. 3, pp.439-467. 
Mergel, I. and Desouza, K.C. (2013) 'Implementing open innovation in the public sector: the case of Challenge.gov.', Public Administration Review, Vol. 73, No. 6, pp.882-890, http://doi.org/ 10.1111/puar.12141

Open Government (n.d.). Electronic Government of the Republic of Kazakhstan, Retrieved 9 May, 2015, from http://open.egov.kz/

Open Government Declaration (2011) Open Government Partnership, Retrieved 23 April, 2015, from http://www.opengovpartnership.org/about/open-government-declaration

Open Government Initiative National Action Plan 2012-2015 [Azerbaijan] (2012) Retrieved 2 February, 2014, from http://www.opengovpartnership.org/file/1052/download

Open Government Partnership (OGP) (2014) Retrieved 28 April, 2014, from http://www. opengovpartnership.org/

Open Government Partnership Open Government Action Plan 2012-2013 for the Republic of Moldova. (2013) Retrieved 8 May, 2015, from http://www.opengovpartnership.org/sites/ default/files/legacy_files/country_action_plans/Moldova Open Government Action Plan 20122013_0.pdf

Open Government Progress Report to the American People (2009) Washington DC, Retrieved 23 September, 2014, from https://www.whitehouse.gov/sites/default/files/microsites/ogiprogress-report-american-people.pdf

Paşcaneana, L. (2014) 'Open government as a tool to develop school choice and school performance: analysis of situation in Republic of Moldova', Journal of School Choice: International Research and Reform, April, pp.37-41. doi: 10.1080/15582159.2014.942179.

Relly, J.E. and Sabharwal, M. (2009) Perceptions of transparency of government policymaking: a cross-national study', Government Information Quarterly, Vol. 26, No. 1, pp.148-157.

The Ministry of Transport and Communications of Kazakhstan (2013) Государственная программа «Информачионный казахстан - 2020» [The state programme 'Information Kazakhstan - 2020'], The Ministry of Transport and Communications of Kazakhstan.

Warf, B. (2014) 'Asian geographies of e-government', Eurasian Geography and Economics, Vol. 55, No. 1, pp.94-110.

Welton, G. (2011) Equal Before the Law? A Study of How Citizens Experience Acess to Justice in Kazakhstan, Kyrgystan and Tajikistan. Retrieved 13 April, 2015, from http://www.crrc.ge/ uploads/files/research_projects/EBL_Research_Report.pdf

Wimmer, M., Scherer, S., Moss, S. and Bicking, M. (2012) 'Method and tools to support stakeholder engagement in policy development', International Journal of Electronic Government Research, Vol. 8, No. 3, pp.98-119.

Концепция открытости федеральных органов исполнительной власти [Concept for Openness of Federal Authorities] (2014) Government of the Russian Federation, Retrieved 2 April, 2014, from http://open.gov.ru/upload/iblock/aaf/aafbe102b0f65b043a23174ebad6136d.doc

Методика мониторинга и оценки открытости федеральных органов исполнительной власти [Methodology for Monitoring and Evaluation of Openness of Federal Authorities] (2013) Government Commission for the Coordination of the Open Government. Retrieved 4 April, 2015, from http://open.gov.ru/upload/iblock/f32/f32f65ebe06aa62bb1a9f247e5c85dda.doc

\section{Note}

${ }^{1}$ We define ideology as shared belief systems that give different practices a certain meaning. Discourse is the expression of an ideology. 